\title{
Relation between Sulfur Pressure and Sticking of Fine Iron Ores in Fluidized Bed Reduction
}

\author{
Shoji HAYASHI, Sougo SAYAMA1) and Yoshiaki IGUCHI
}

Department of Materials Science and Engineering, Nagoya Institute of Technology, Gokiso-cho, Showa-ku, Nagoya, Aichi-ken, 466 Japan.

1) The Government Industrial Development Laboratory, Hokkaido, Tsukisamu-Higashi, Toyohira-ku, Sapporo, Hokkaido, 004 Japan.

(Received on October 6, 1989; accepted in the final form on April 20, 1990)

\begin{abstract}
Fourteen kinds of iron ore fines $(0.015-0.021 \mathrm{~cm}$ diameter) were reduced to iron in a laboratory batch fluidized bed with a $90 \% \mathrm{CO}-10 \% \mathrm{CO}_{2}$ mixture (flow rate: 8 times the minimum fluidization velocity $U_{m f}$ ) at $700-900^{\circ} \mathrm{C}$ to investigate the relation between sticking behavior and sulfur activity in gas phase of bed during metallization $\left(a_{S}\right)$, which could be evaluated from chemical analysis of sulfur species in exhausted gas, relative to iron/iron sulfide equilibrium.

Values of $a_{\mathrm{S}}$ obtained in all of tests were in the range of $0.01-1$. The tests showing middle sulfur activities around 0.1 , fell into sticking state soon after initial metallization, accompanied with long iron whiskers at higher temperatures. The tests showing activities other than the above conditions, induced short iron whiskers and porous or plain irons, indicating fluidized state until higher reduction degrees at lower temperatures. These temperature and sulfur activity dependences of product morphologies, which were in nearly agreement with authors' previous researches about abnormal swelling during reduction of iron oxide pellets prepared from reagent, corresponded to a sticking tendency of bed. These results give one reasonable idea by which the ore kind dependence of sticking can be interpreted.
\end{abstract}

KEY WORDS: iron ores; laboratory fluidized bed reduction; sticking; sulfur potential; iron morphology; temperature dependence; ore kind dependence.

\section{Introduction}

The fluidized bed reduction process of iron ores had developed as one of direct reduction processes in ironmaking. Recently it is also applicable to a prereduction process of ores within several smelting reduction processes as alternatives to blast furnace. ${ }^{1-3)}$ However, only a few successful operation have been found in an industrial scale. The cause is attributed to the most serious problem of defluidization of bed through sticking. ${ }^{4,5}$ ) This had been detailed by some workers including Okura, $\left.{ }^{6}\right)$ who observed that when the bed reached a defluidized state, numerous fine whiskers of iron were intertwisted together with small connection. These phenomena are frequently found in several ores at higher temperatures such as $900^{\circ} \mathrm{C}$. The temperature dependence of sticking is likely to coincide with a general tendency for whiskers to be formed with temperature. One of another troublesome problems is that this phenomena is strongly dependent upon the kind of ores. ${ }^{5)}$ However, these detailed mechanism remain unknown. Under these circumstance, many trials to avoid sticking had been made: addition of foreign materials such coke ${ }^{7,8)}$; coating of $\mathrm{MgO}$ and carbon ${ }^{9)}$; etc. But, these methods are limited in some cases. Therefore, attempts to modify motion of bed by stirring, ${ }^{10)}$ rotation, ${ }^{11}$ and circulating ${ }^{12)}$ have been also continued in present time.
Present authors have investigated abnormal swelling during reduction in sulfur bearing gas using iron oxide pellets produced from reagent. ${ }^{13-15}$ ) Main results were as follows: this swelling occurs due to appearance of fibrous metallic iron; the principal experimental condition to realize these phenomena is the intermediate reduction rate of wustite under the range of $0.01-1$ as the sulfur activity in gas phase during metallization, $a_{\mathrm{S}}{ }^{*}$; the maximum swelling occurs around $900^{\circ} \mathrm{C}$ and $a_{\mathrm{s}}=0.1$ with long iron whiskers; and additives such as $\mathrm{CaO}$ promoting the abnormal swelling are operated as an assistant role regardless of any reduction history.

Based on above results, the reduction test of 14 kinds of iron ores with a $\mathrm{CO}-\mathrm{CO}_{2}$ mixture has been carried out in the present work using a laboratory batch fluidized bed reactor. The sulfur activity in gas phase of bed during reduction stage of wustite to metallic iron, which is derived from traces of sulfur present in ores, can be obtained from exit gas analysis. The sulfur activity dependence of sticking behavior in fluidized bed reduction of each ore was investigated in relation to the results such as morphology of metallic iron.

\section{Experimentals}

\subsection{Specimens}

Chemical compositions of test ores are shown in

\footnotetext{
* In this work, $a_{\mathrm{S}}$ is defined as $\left(P_{C O S} / P_{\mathrm{CO}}\right) /\left(P_{C O S} / P_{\mathrm{CO}}\right)_{e}$, where $\left(P_{C O S} / P_{\mathrm{CO}}\right)_{e}$ is the gas ratio under iron and iron sulfide equilibrium. ${ }^{13,18)}$
} 
Table 1. Each of these ores is crushed, screened with water, and dried at $150^{\circ} \mathrm{C}$ to prepare particles of $0.015-0.021 \mathrm{~cm}$ diameter. The table also shows main mineral phases detected by a powder X-ray diffraction method. Sayama et al. $\left.{ }^{17}\right)$ had indicated characteristics of ores $\mathrm{A}-\mathrm{J}$ as below.

Ore A shows a typical lamellar structure, which is subjected to dynamic metamorphism. Hematite is a compacted ore and its crystals are arranged with directionality. The crystal also tends to crack into a plate form. Goethite is not observed, but a small amount of quartz exists as gangue. Ore B is massive and contains mainly hematite. The grain boundary shows a mosaic structure. The structure of ore $\mathrm{C}$ is similar to that of ore B. The ore includes a small amount of goethite. Ore D contains an abundance of goethite, coexisting with hematite. Hematite is porous and the grain boundary is indistinct. In ore E columnar developed hematites are observed. Grain boundaries of such kinds of crystals are clearly observed, but the ore is not stratified, differing from Brazil ore. The deposit of ore $G$ is considerably folded and subjected to a strong metamorphism. The ore contains hematite and a large amount of quartz. In ore $\mathrm{H}$ hematite is developed in magnetite. The deposit which is a contact metasomatism deposit akin to the Marcona deposit, abounds in alkali components and contains pyrite too. In ore $I$, an abundance of pyrite is observed and the ore presents a structure similar to that of Santafe ore. Ore J contains porous magnetite. But, hematite cannot be observed. This ore is classified under banded ore deposits that had been subjected to dynamic metamorphism. The ore contains much quartz as gangue.

\subsection{Experimental Procedure}

Batches of $20 \mathrm{~g}$ of ore were reduced under fluidized state in a stainless steel tube (2.2 $\mathrm{cm}$ inner diameter) with a $90 \% \mathrm{CO}-10 \% \mathrm{CO}_{2}$ mixture at $700-900^{\circ} \mathrm{C}$. The bed is supported by a distributor with opening of $105 \mu \mathrm{m}$. The experimental apparatus is constructed as shown in Fig. 1. The temperature of bed is monitored by a thermocouple at its center. The bed is holded by nitrogen much enough to fluidize during ascending and descending periods between room and reaction temperatures. For the purpose of following the reaction level of ore during reduction, a portion of off-gas is always flowed bypassing into an oxygen sensor using a zirconia solid electrolyte with a reference of air. For example, Fig. 2 shows the electric motive force of the sensor (EMF) obtained during reduction of ore A (Brazil ore). This variation of EMF, which is analogous to those measured by Sheasby and Gransden, ${ }^{18)}$ informs roughly the reduced level of ore. Based on this EMF observation, the gas exhausted by reduction beyond wustite stage is introduced to $\mathrm{SO}_{2}$ absorbents via an oxidizing furnace, where the total sulfur species are deter-

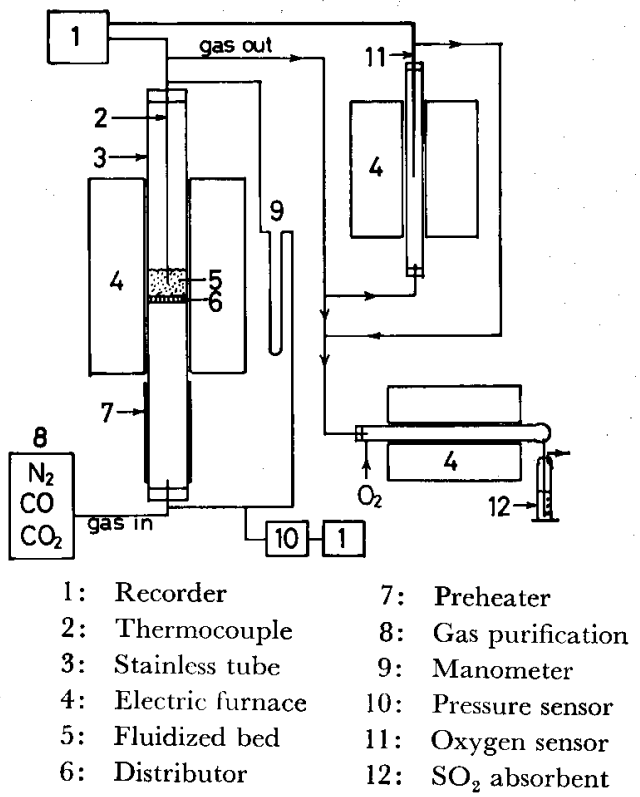

Fig. 1. Experimental apparatus.

Table 1. Chemical composition of iron ore. (wt \%)

\begin{tabular}{|c|c|c|c|c|c|c|c|c|c|c|c|}
\hline Name & Ore & T.Fe & $\mathrm{FeO}$ & $\mathrm{SiO}_{2}$ & $\mathrm{Al}_{2} \mathrm{O}_{3}$ & $\mathrm{CaO}$ & $\mathrm{MgO}$ & $\mathrm{S}^{* 2}$ & $\mathrm{Na}_{2} \mathrm{O}^{\star 2}$ & $\mathrm{~K}_{2} \mathrm{O}^{* 2}$ & $\begin{array}{c}\text { Main mineral } \\
\text { phases }\end{array}$ \\
\hline Brazil & $\mathrm{A}$ & 65.20 & 0.20 & 4.29 & 1.32 & - & 0.14 & 0.0034 & 0.005 & 0.003 & $H$ \\
\hline Swaziland & B & 63.65 & 0.18 & 4.68 & 2.15 & - & - & 0.0058 & 0.018 & 0.019 & $H$ \\
\hline Hamersley & C & 62.10 & 0.22 & 4.45 & 2.56 & 0.22 & - & 0.0164 & 0.018 & 0.012 & $H$ \\
\hline Portlady & $\mathrm{D}$ & 61.19 & 0.20 & 1.63 & 3.30 & - & 0.10 & 0.0253 & 0.009 & 0.010 & $H, G$ \\
\hline Goldsworthy & $\mathrm{E}$ & 65.85 & 0.08 & 3.30 & 1.25 & 0.10 & - & 0.0200 & 0.028 & 0.010 & $H$ \\
\hline Krivoy-Rog & $\mathrm{G}$ & 58.52 & 3.15 & 15.62 & 1.04 & 0.30 & 0.18 & 0.0110 & 0.013 & 0.016 & $H, Q$ \\
\hline Santafe & $\mathbf{H}$ & 63.29 & 14.29 & 4.98 & 0.97 & 1.50 & 1.10 & 0.1183 & 0.029 & 0.030 & $M, \widetilde{H}$ \\
\hline Marcona & I & 63.22 & 15.29 & 5.08 & 0.82 & 1.08 & 1.76 & 1.441 & 0.063 & 0.051 & $M, H, P$ \\
\hline Mosan & $\mathrm{J}$ & 58.47 & 22.55 & 17.25 & 0.42 & 0.71 & 0.59 & 0.0290 & 0.012 & 0.030 & $M, Q$ \\
\hline Mt. Newman & $\mathrm{K}$ & 61.48 & 0.29 & 6.47 & 2.76 & 0.06 & 0.06 & 0.0113 & 0.014 & 0.037 & $H$ \\
\hline Dempo & $\mathbf{L}$ & 62.60 & 2.04 & 2.44 & 2.26 & 0.03 & 0.08 & 0.0320 & 0.014 & 0.032 & $H, G$ \\
\hline Romeral & $\mathbf{M}$ & 66.25 & 28.42 & 3.91 & 0.81 & 1.23 & 0.79 & 0.0670 & 0.031 & 0.026 & $M$ \\
\hline Rio Doce* & $\mathrm{O}$ & 62.31 & 0.46 & 5.82 & 1.26 & 0.15 & 0.13 & 0.0102 & 0.007 & 0.007 & $H, Q$ \\
\hline Taharoa* & $\mathbf{S}$ & 56.85 & 18.57 & 2.96 & 3.68 & 1.51 & 3.55 & 0.0181 & 0.015 & 0.012 & $M$ \\
\hline
\end{tabular}

Ores A-M: Ref. 17)

* : Kobe Steel, Ltd.

*2: $150-210 \mu \mathrm{m}$, Alkali contents are those soluble in hot $\mathrm{HCl}$ solution.

*3: $H$; Hematite, $M$; Magnetite, $G$; Goethite, $Q$; Quartz, $P$; Pyrite 


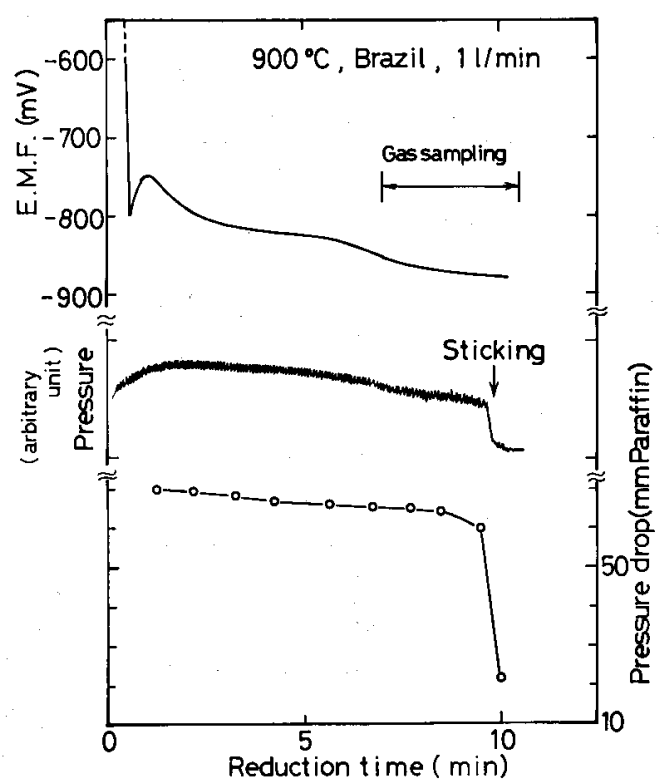

Fig. 2. Variation of EMF, pressure, and pressure drop during reduction.

mined by means of acidimetry using $\mathrm{NaOH}$ solution (JIS K2541-1984). Thermodynamical consideration $^{13)}$ shows that $C O S$ is most stable as sulfur species in present reduction condition, so that $P_{\text {cos }} / P_{\mathrm{CO}}$ in bed is evaluated as a mean value during gas sampling assuming that gas phase in bed is under $\mathrm{Fe} / \mathrm{FeO}$ equilibrium. ${ }^{19)}$ This comes from that present EMF measurement cannot assess the exact oxygen pressure in bed. The sticking time, $t_{s}(\mathrm{~s})$, as seen in the figure, can be detected from both abrupt changes of an oscillating total pressure in upstream of gas and pressure drop through bed. After sticking, the ore bed is cooled until room temperature. Fractional reduction of ores, $R$, is measured by the reoxidation method $\left(950^{\circ} \mathrm{C}\right.$ for $3.5 \mathrm{~h}$ in air), based on the complete oxidation of total iron in ores.

\section{Experimental Results}

\subsection{Gas Volume Dependence}

Substitution in the equation of minimum fluidization velocity, $U_{m f}=\rho_{s} g d^{2} / 1650 \mu,{ }^{21)}$ derived from the equation of Wen and $\mathrm{Yu}^{20)}$ of the density of solid $\rho_{s}=5.26 \mathrm{~g} / \mathrm{cm}^{3}$, the particle diameter $d=0.021 \mathrm{~cm}$, and the nitrogen viscosity $\mu_{\mathrm{N}_{2}}=4.53 \times 10^{-4} \mathrm{~g} / \mathrm{cms}$ gives $U_{m f}$ $=3.05 \mathrm{~cm} / \mathrm{s}$ at $900^{\circ} \mathrm{C}$. This value agreed with the minimum fluidization velocity measured with nitrogen at $900^{\circ} \mathrm{C}, U_{m f}^{m}=3.15 \mathrm{~cm} / \mathrm{s}$. Because $\mu_{\mathrm{co}}=4.58 \times 10^{-4}$ and $\mu_{\mathrm{CO}_{2}}=4.26 \times 10^{-4} \mathrm{~g} / \mathrm{cms}$ at $900^{\circ} \mathrm{G}_{,}{ }^{22)} U_{m f}$ using a $\mathrm{CO}-\mathrm{CO}_{2}$ mixture should be in nearly agreement with $U_{m f}^{M}$ using nitrogen. For example, a nitrogen gas volume of $1.5 \mathrm{l} / \mathrm{min}$ at room temperature is corresponding to a linear velocity at $900^{\circ} \mathrm{C}$ of $26.3 \mathrm{~cm} / \mathrm{s}$ (8.3 times $\left.U_{m_{f}}^{M}\right)$. Because Froud number becomes $F r=U^{2} / g d=39.1>1$ for this condition, a bubbling type fluidization bed will be operated in the present work.

Gas volume dependence of $t_{s}$ values was examined

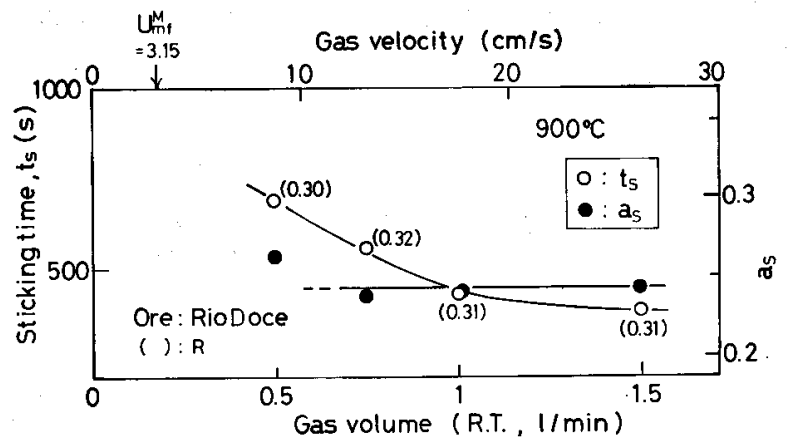

Fig. 3. Relation between gas volume and sticking time.

at $900^{\circ} \mathrm{C}$ using ore $\mathrm{O}$ (Rio Doce ore). The result is shown in Fig. 3. The values decrease with increasing gas volume until $1.0 \mathrm{l} / \mathrm{min}$ and reach nearly a plateau at $1.5 \mathrm{l} / \mathrm{min}$. Sticking of each experiment seems to occur at initial metallization stage due to $R=0.30$ 0.32 . These results suppose that the reduction until wustite stage of ore $\mathrm{O}$ below a condition of $1.0 \mathrm{l} / \mathrm{min}$ probably progresses under gas supplying control and that the reduction at a condition of $1.5 \mathrm{l} / \mathrm{min}$ will proceed with some of chemical reaction resistances between gas and solid. Because the reduction from original ore until wustite stage is generally faster than that after the stage, the latter reduction in the range of $1.0-1.5 \mathrm{l} / \mathrm{min}$ will proceed with more resistances for both processes of reaction and diffusion within ore particles, meaning lowering of gas utilization. But, the gas volumes of 1.0 and $1.5 \mathrm{l} / \mathrm{min}$ were sclected as main ones. This is owing to the cause that the experiments by much volume enabling more intensive stirring of bed is more favorable for ascertaining the difference among sticking of ores.

As the values of $a_{\mathrm{s}}$, corresponding to $P_{\text {cos }} / P_{\mathrm{co}}$, is almost constant with increasing gas volumes, as seen in Fig. 3, the desulfurization rate of ore $O$ would be controlled by gas starvation.

\subsection{Relation between Reduction Behavior and Sulfur Ac- tivity}

Ores were reduced in gas volumes of 1.0 and 1.5 $l /$ min at $900^{\circ} \mathrm{C}$. The relations between the value of $t_{s}$ or the partial reduction time under fluidization and $\log a_{\mathrm{S}}$ are plotted together with fractional reduction in parentheses, as shown in Figs. 4 and 5. The iron morphology observed under SEM after partial reduction is shown in Fig. 6 for the condition of $1.5 \mathrm{l} / \mathrm{min}$ at $900^{\circ} \mathrm{G}^{*}{ }^{*}$ In most of cases, fibrous irons are formed. They are classified into $L, M$, and $S$ type iron whiskers, according to their lengths rather than numbers.

Concerning Fig. 5, ore $\mathrm{S}$ of $\log a_{\mathrm{S}}=-1.96$ was under fluidization without whiskers $(R=0.44)$. Ore $\mathrm{B}$ of $\log a_{\mathrm{s}}=-1.11$ formed $S$ type iron whiskers with sticking $(R=0.42)$. Ore $\mathrm{O}$ of $\log a_{\mathrm{S}}=-0.62$ gave $L$ type iron whiskers to stick $(R=0.31)$, indicating the shortest value of $t_{s}$. Ore I of $\log a_{\mathrm{s}}=-0.22$ presented $S$ type iron whiskers to stick, having a relatively larger

* Ores D, O, and I referred to Figs. $9(\mathrm{c}), 10(\mathrm{c})$, and $11(\mathrm{c})$. 
Marks $L, M, S$, and $\mathcal{N}$ are explained in Fig. 6 . Parentheses: Fractional reduction

Fig. 4.

Sulfur activity dependence of reduction behavior at $900^{\circ} \mathrm{G}$ $(1.0 \mathrm{l} / \mathrm{min})$.

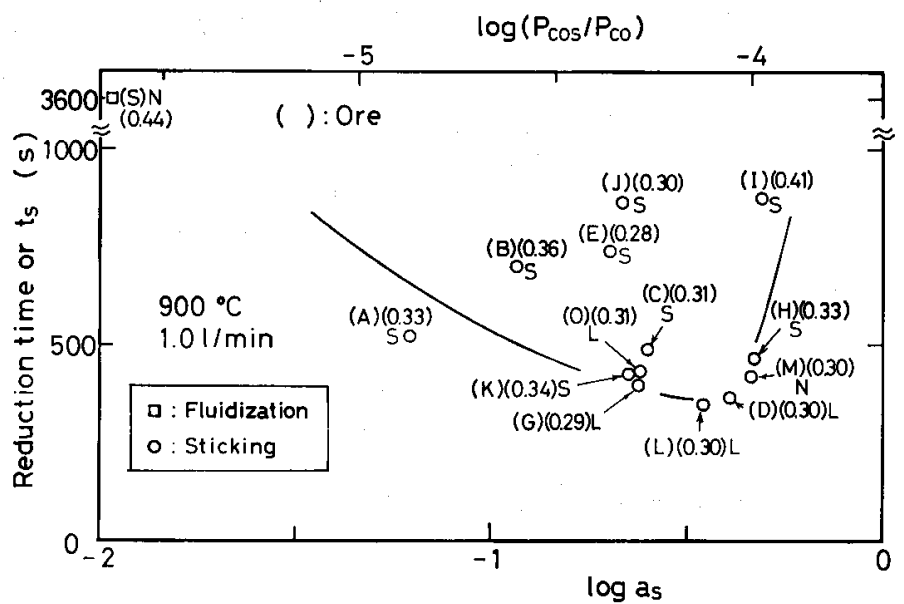

Marks $L, M, S$, and $\mathcal{N}$ are explained in Fig. 6 .

Parentheses: Fractional reduction

Fig. 5.

Sulfur activity dependence of reduction behavior at $900^{\circ} \mathrm{C}$ $(1.5 \mathrm{l} / \mathrm{min})$.
Fig. 7.

Sulfur activity dependence of reduction behavior at $800^{\circ} \mathrm{C}$ $(1.5 \mathrm{l} / \mathrm{min})$.

value of $R=0.46$. Ore $\mathrm{M}$ sticked in spite of occurrence of plain irons as shown in Fig. 6(j). This is likely owing to the formation of active surface. The variations of $t_{s}$ values and iron morphologies with $\log a_{\mathrm{S}}$ in case of $1.0 \mathrm{l} / \mathrm{min}$ as indicated in Fig. 4 are in nearly agreement with those in case of $1.5 \mathrm{l} / \mathrm{min}$ (Fig. 5) except larger values of $t_{s}$ as a whole. Such a sulfur activity dependence of iron morphology, as expected, also corresponds to the authors' previous results $^{13}$ that abnormal swelling during reduction of wustite pellets with $\mathrm{CO}-\mathrm{CO}_{2}$ mixtures existed in the range of 0.01-1 of $a_{\mathrm{s}}$ accompanied with iron whiskers.

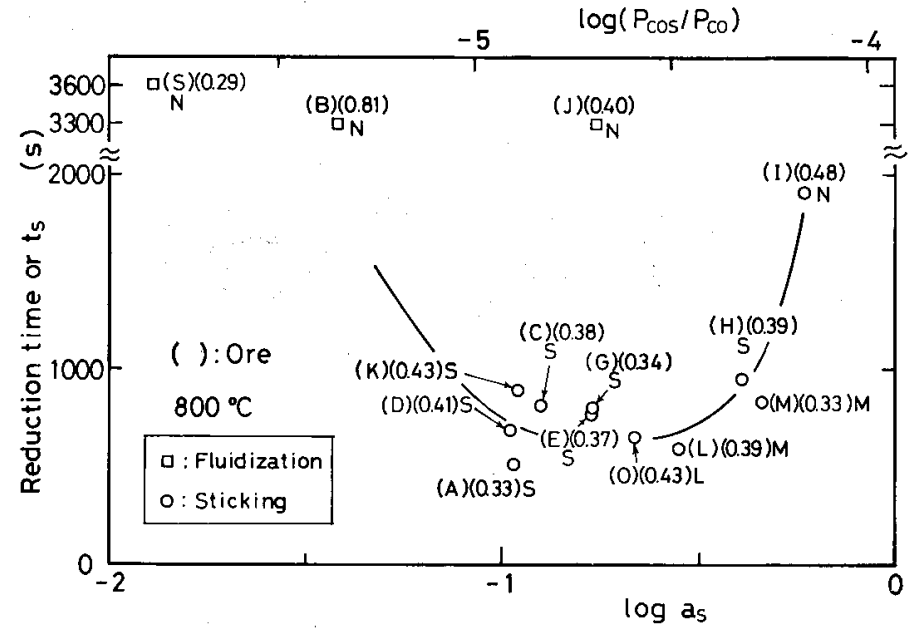

Fig. 7 shows the results at $800^{\circ} \mathrm{C}$, in which ores $\mathrm{B}$ and $\mathrm{J}$ are joined as those being fluidized. Ore $\mathrm{J}$ forms no whiskers in spite of a favorable condition of intermediate $a_{\mathrm{s}}$ and shows the slow reduction ( $R=$ 0.40 ) due to magnetite ore. Ore I sticked regardless of no whiskers $(R=0.48)$, probably attributed to the active surface of porous iron. Excepting larger values of $t_{s}$ at $800^{\circ} \mathrm{C}$ than at $900^{\circ} \mathrm{C}$, the sulfur activity dependence of iron morphology at the former temperature is roughly similar to that at the latter. Moreover, the values of $R$ are greater at $800^{\circ} \mathrm{C}$ than at $900^{\circ} \mathrm{C}$ as a whole, resulting in a less sticking tendency. 

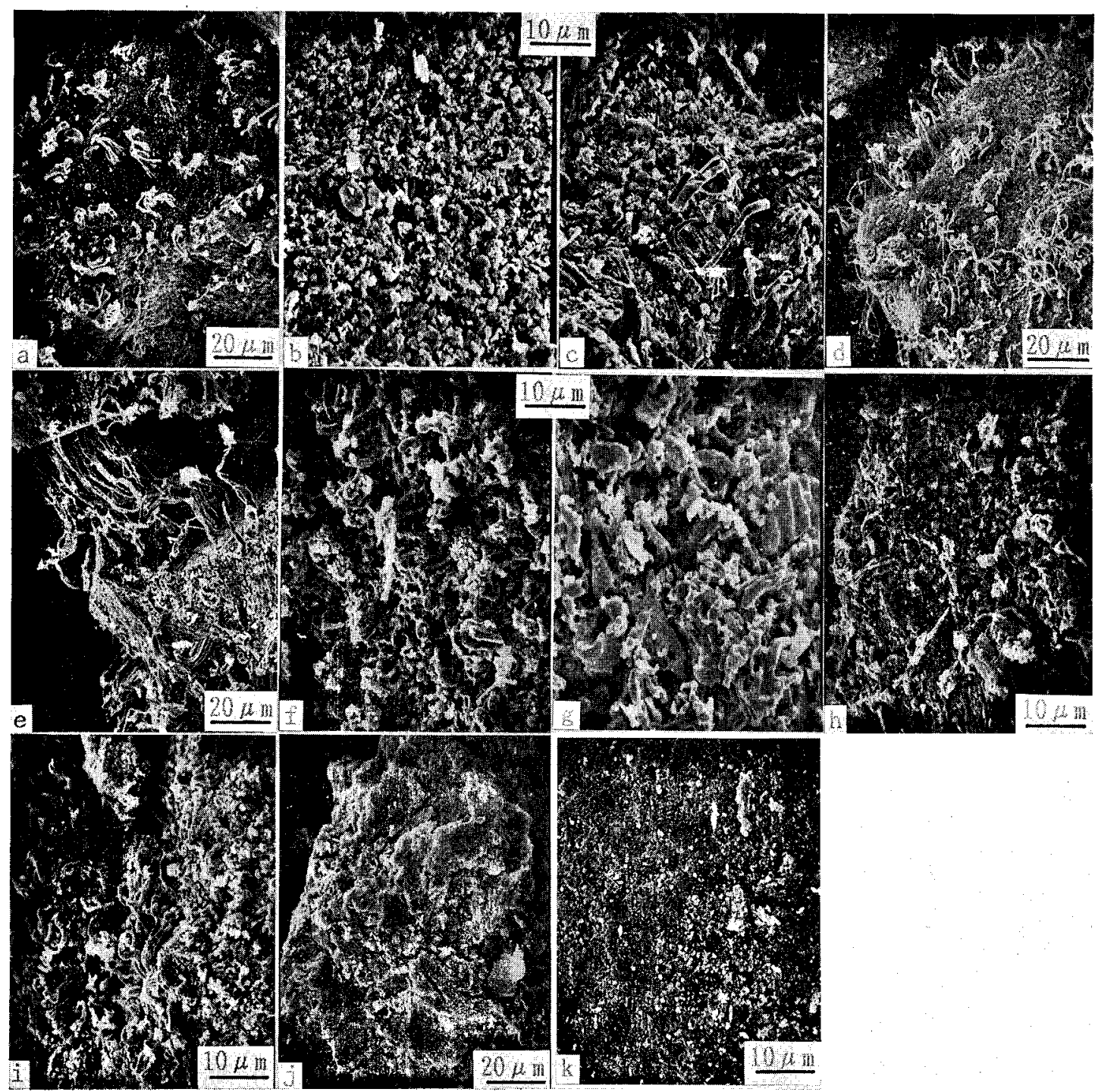

\begin{tabular}{lccccccccccc}
\hline No. & (a) & (b) & (c) & (d) & (e) & (f) & (g) & (h) & (i) & (j) & (k) \\
\hline Ore & $\mathrm{A}$ & $\mathrm{B}$ & $\mathrm{C}$ & $\mathrm{E}$ & $\mathrm{G}$ & $\mathrm{H}$ & $\mathrm{J}$ & $\mathrm{K}$ & $\mathrm{L}$ & $\mathrm{M}$ & $\mathrm{S}$ \\
\hline $\log a_{\mathrm{S}}$ & -1.30 & -1.11 & -0.55 & -0.66 & -0.56 & -0.39 & -0.50 & -0.80 & -0.55 & -0.36 & -1.96 \\
$*$ & $M$ & $S$ & $S$ & $M$ & $L$ & $S$ & $S$ & $M$ & $L$ & $\mathcal{N}$ & $\mathcal{N}$ \\
$* *$ & $S t$ & $S t$ & $S t$ & $S t$ & $S t$ & $S t$ & $S t$ & $S t$ & $S t$ & $S t$ & $F$ \\
\hline
\end{tabular}

* Product morphology; Long and short iron whiskers named $L$ and $S$ type iron whiskers, respectively. $M$ type iron whisker means middle one.

Mark $\mathcal{N}$ means porous or plain iron, including the state prior to metallization.

** $S_{t}:$ Sticking, $F$ : Fluidization.

Fig. 6. External views of partial reduced ores at $900^{\circ} \mathrm{G}(1.5 / / \mathrm{min})$.

Fig. 8 shows the results at $700^{\circ} \mathrm{C}$. Inside low sulfur activities, ores $\mathrm{K}, \mathrm{L}$, and $\mathrm{D}$ were joined as those under fluidization other than ores $\mathrm{S}$ and $\mathrm{B}$, despite that ore $\mathrm{K}$ formed $S$ type iron whiskers. These ores indicate higher reduction degrees except ore $\mathbf{S}$ of iron sand $(R=0.13)$. Inside high sulfur activities, ore I was fluidized besides ore $\mathrm{J}$. Within the field between both above activities, as expected, iron whiskers of $S$ type were formed for a few ores, leading to sticking of bed.

Table 2 summarizes the variations of product morphology and fluidization state with tcmperatures. The temperature dependence of iron morphology for typical ores is showed as below. Ore D having middle activities diminishes the formation of fibrous irons with decreasing temperatures as shown in Fig. 9, to be under fluidization at $700^{\circ} \mathrm{C}$. However, ore $\mathrm{O}$ having the same activity as ore $\mathrm{D}$ sticked even at $700^{\circ} \mathrm{C}$ due to $L$ type iron whiskers as shown in Fig. 10 , to be in lower reduction level of $R=0.31-0.43$ at all temperatures. It is also found that the whiskers become finer at low temperatures. Ore I having higher sulfur activities suppresses the formation of whiskers as shown in Fig. 11 with more reduction degrees than ore $\mathrm{O}$, indicating the fluidization state at $700^{\circ} \mathrm{C}$. 


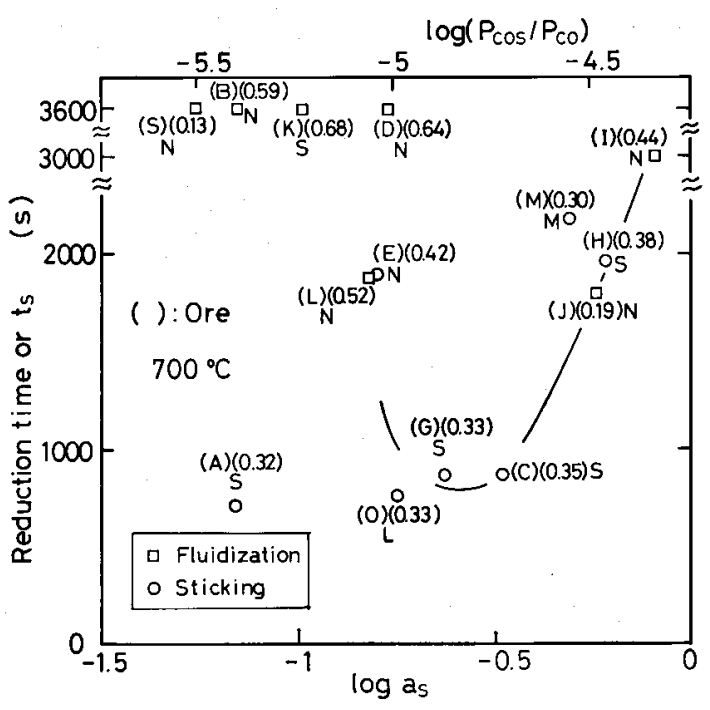

Fig. 8. Sulfur activity dependence of reduction behavior at $700^{\circ} \mathrm{C}(1.5 \mathrm{l} / \mathrm{min})$.
Table 2. Product morphology and fluidization behavior.

\begin{tabular}{|c|c|c|c|c|}
\hline \multirow{2}{*}{ Ore } & \multirow{2}{*}{$\begin{array}{c}700^{\circ} \mathrm{C} \\
1.5 \mathrm{l} / \mathrm{min}\end{array}$} & \multirow{2}{*}{$\begin{array}{c}800^{\circ} \mathrm{C} \\
1.5 \mathrm{l} / \mathrm{min}\end{array}$} & \multicolumn{2}{|c|}{$900^{\circ} \mathrm{C}$} \\
\hline & & & $1.0 \mathrm{l} / \mathrm{min}$ & $1.5 \mathrm{l} / \mathrm{min}$ \\
\hline A & $S, S t$ & $S, S t$ & $S, S t$ & $M, S t$ \\
\hline B & $\mathcal{N}, F$ & $\mathcal{N}, F$ & $s, S t$ & $S, S t$ \\
\hline $\mathrm{C}$ & $S, S t$ & $S, S t$ & $S, S t$ & $S, S t$ \\
\hline $\mathrm{D}$ & $\mathcal{N}, F$ & $S, S t$ & $L, S t$ & $L, S t$ \\
\hline $\mathrm{E}$ & $\mathcal{N}, S t$ & $S, S t$ & $S, S t$ & $M, S t$ \\
\hline G & $S, S t$ & $S, S t$ & $L, S t$ & $L, S t$ \\
\hline $\mathrm{H}$ & $S, S t$ & $S, S t$ & $S, S t$ & $S, S t$ \\
\hline I & $\mathcal{N}, F$ & $\mathcal{N}, S t$ & $S, S t$ & $S, S t$ \\
\hline $\mathrm{J}$ & $\mathcal{N}, F$ & $\mathcal{N}, F$ & $S, S t$ & $S, S t$ \\
\hline $\mathbf{K}$ & $S, F$ & $S, S t$ & $S, S t$ & $M, S t$ \\
\hline $\mathrm{L}$ & $\mathcal{N}, F$ & $M, S t$ & $L, S t$ & $L, S t$ \\
\hline $\mathbf{M}$ & $M, S t$ & $M, S t$ & $\mathcal{N}, S t$ & $\mathcal{N}, S t$ \\
\hline 0 & $L, S t$ & $L, S t$ & $L, S t$ & $L, S t$ \\
\hline $\mathbf{S}$ & $\mathcal{N}, F$ & $\mathcal{N}, F$ & $\mathcal{N}, F$ & $\mathcal{N}, F$ \\
\hline
\end{tabular}

Marks $L, M, S, \mathcal{N}, S t$, and $F$ are referred to Fig. 6 .

Portlady (Ore D), (1.5 l/min)

\begin{tabular}{cccccc}
\hline No. & $\begin{array}{c}\text { Red. } \\
\text { temp. }\end{array}$ & $R$ & $\log a_{\mathrm{S}}$ & $*$ & $* *$ \\
\hline (a) & $700^{\circ} \mathrm{C}$ & 0.64 & -0.77 & $\mathcal{N}$ & $F$ \\
(b) & $800^{\circ} \mathrm{C}$ & 0.41 & -0.98 & $S$ & $S t$ \\
(c) & $900^{\circ} \mathrm{C}$ & 0.37 & -0.58 & $L$ & $S t$
\end{tabular}

*,**: Referred to Fig. 6.

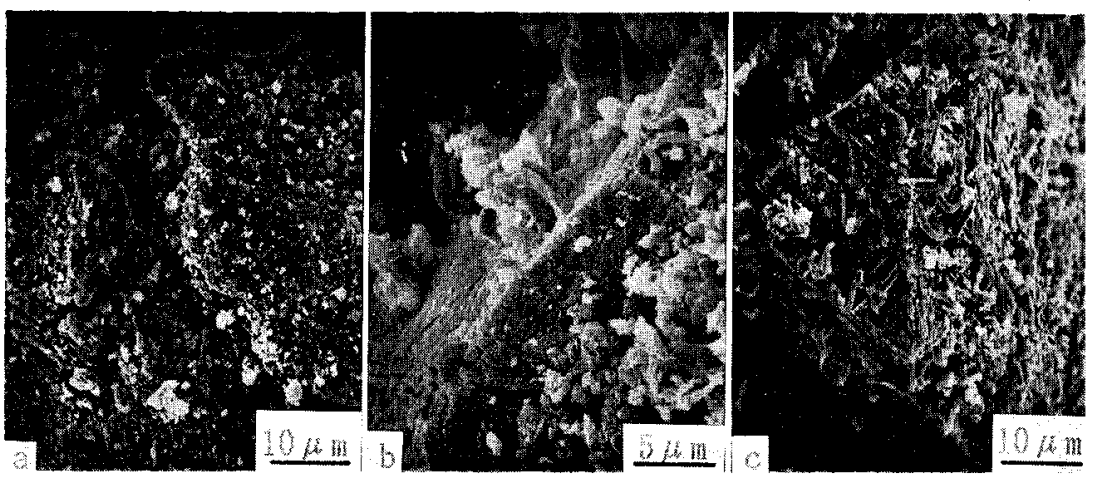

Fig. 9. External views of partial reduced ores.

Rio Doce (Ore O), $(1.5 \mathrm{l} / \mathrm{min})$

\begin{tabular}{cccccc} 
No. & $\begin{array}{c}\text { Red. } \\
\text { temp. }\end{array}$ & $R$ & $\log a_{\mathrm{S}}$ & $*$ & $* *$ \\
\hline (a) & $700^{\circ} \mathrm{C}$ & 0.33 & -0.75 & $L$ & $S t$ \\
(b) & $800^{\circ} \mathrm{C}$ & 0.43 & -0.66 & $L$ & $S t$ \\
(c) & $900^{\circ} \mathrm{C}$ & 0.31 & -0.62 & $L$ & $S t$ \\
\hline
\end{tabular}
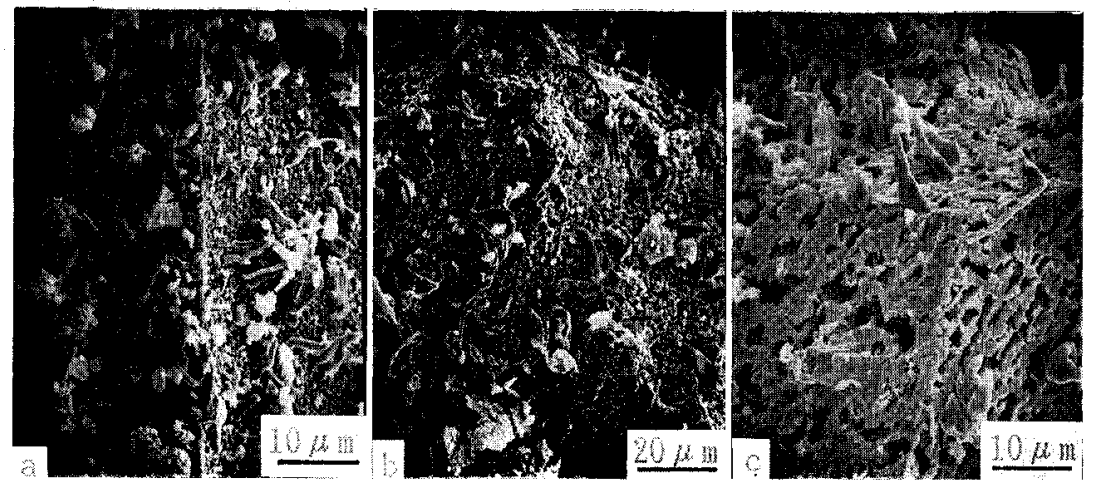

Fig. 10. External views of partial reduced ores.

\subsection{Relation between Sulfur in Ore and Its Potential}

Relation between the initial sulfur content in ore $(\% \mathrm{~S})_{0}$ and the sulfur activity during metallization $a_{\mathrm{s}}$ is plotted at $900^{\circ} \mathrm{C}$ as shown in Fig. 12. Both variables have some relation each other for both gas volumes, except ore $S$ showing the lowest value of $a_{\mathrm{S}}$.

The amount of sulfur gasified during reduction from ore to wustite stage, which has no influence to morphology of iron, was determined for 8 kinds of ores $\left(900^{\circ} \mathrm{C}, 1.0 \mathrm{l} / \mathrm{min}\right)$. The average ratios of the gasification before wustite stage against that beyond the stage amount to $1.4-1.8$ for ores $\mathrm{C}, \mathrm{D}, \mathrm{G}, \mathrm{K}$, and $\mathrm{O}$ (hematite ore), and $3.3-7.8$ for ores $\mathrm{H}$ to $\mathrm{J}$ (magnetite ore).

\section{Discussion}

\subsection{Sulfur Potential}

The results in Fig. 12 can be explained as follows. As the desulfurization rate of ore $\mathrm{O}$ having a low sulfur content as described in Sec. 3.1 would be controlled under gas starvation, the chemical reaction 

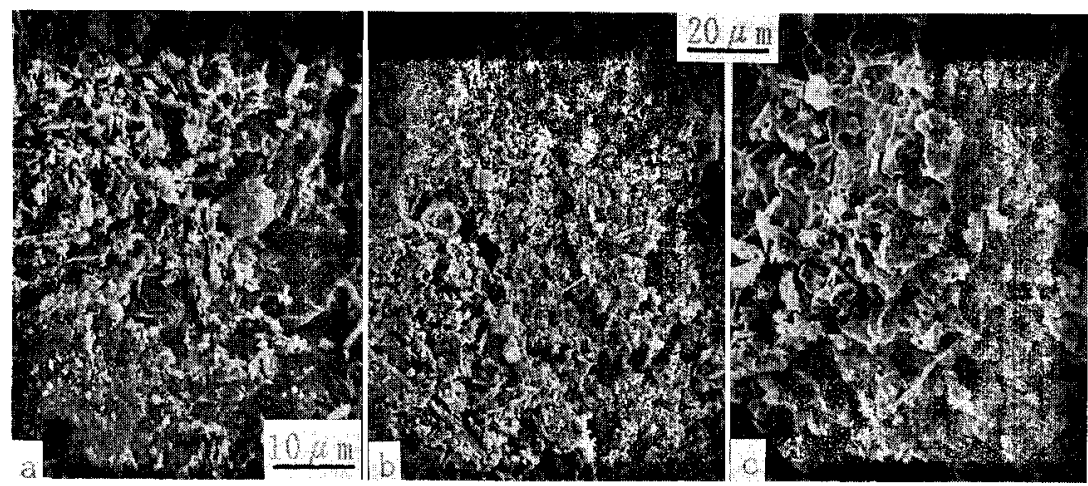

Marcona (Ore I), (1.5 l/min)

\begin{tabular}{cccccc}
\hline No. & $\begin{array}{c}\text { Red. } \\
\text { temp. }\end{array}$ & $R$ & $\log a_{\mathrm{S}}$ & $*$ & $* *$ \\
\hline (a) & $700^{\circ} \mathrm{C}$ & 0.44 & -0.09 & $\mathcal{N}$ & $F$ \\
(b) & $800^{\circ} \mathrm{C}$ & 0.47 & -0.23 & $\mathcal{N}$ & $S t$ \\
(c) & $900^{\circ} \mathrm{C}$ & 0.46 & -0.22 & $S$ & $S t$ \\
\hline
\end{tabular}

Fig. 11. External views of partial reduced ores.

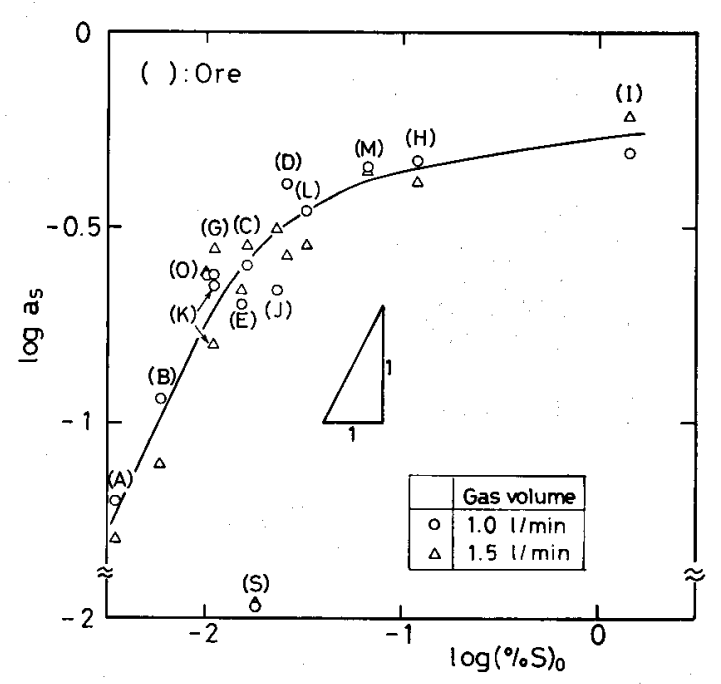

Fig. 12. Relation between sulfur activity and sulfur content in ore at $900^{\circ} \mathrm{C}$.

between sulfur species in ore and gas might be apparently under equilibrium, suggesting that $a_{\mathrm{S}}$ is proportional to $(\% \mathrm{~S})_{0}$. As expected, the gradient between both variables shown in Fig. 12 seems to be nearly unity in the range of $\log (\% \mathrm{~S})_{0}<-1.8$. However, the gradient gradually becomes less than unity over this content. This fact suggests an increment of chemical reaction resistance including relatively lowering of reaction areas for the desulfurization of ore. For the case of ore $\mathbf{I}$ containing a large amount of pyrite, if the chemical reaction rate is enough great and gangues are inert, the results of $a_{\mathrm{S}}=1$ in gas phase should be realized under the existence of metallic iron. However, the actural results reveal that $a_{\mathrm{S}}<1$. Nevertheless, it is probably that the reduction of each ore proceeds under the value close to $a_{\mathrm{s}}$ obtained in this figure.

According to authors' basic research, ${ }^{23)}$ it is expected that sulfur species chemisorbed on solids such as reduced iron might control markedly iron morphology, being dependent upon the sulfur potential. Consequently, it may be necessary to examine their adsorption behavior on solid phases and their interfaces and to observe in detail the phenomena related to nucleation and growth of metallic iron.

\subsection{Comparison of Sticking and Swelling Phenomena}

A series of authors' studies ${ }^{13-15)}$ about abnormal swelling indicated that the swelling depends on length rather than number of iron whiskers. On the other hand, Langston and Stephens ${ }^{24}$ ) had studies self-agglomeration during fluidized bed reduction and presented that the tendency for particles to stick together (stickness) is directly proportional to their adhesive force and surface area of contact, and inversely proportional to their momentum. Presumably, the longer the whiskers (as seen in Fig. 6(e)) and the higher the surface activity of iron, the more intensive the adhesive force. The area of contact possibly increases with increasing both length and number of whiskers. Because the momentum is constant in case of a definite gas volume, the former two variables probably control the stickness.

As described in Sec. 3.2, most of fibrous irons of $L$ type were found around intermediate $a_{\mathrm{S}}$, where the bed was easily sticked with less values of $t_{s}$ and $R$. In the cases other than these $a_{\mathrm{s}}, S$ type iron whiskers and porous or plain irons were formed to give slightly larger values of $t_{s}$ and $R$ and to realize the fluidization state at lower temperatures. As a conclusion, the temperature and sulfur activity dependences of $t_{s}$ and $R$ agree with those concerning the swelling behavior of pellets described in the beginning. ${ }^{13-15)}$

The result that iron morphology produced from many kinds of iron ores depends on sulfur activity in gas phase cannot be almost found out in other studies, which might present one of mechanisms interpreting clearly difference of sticking behavior among various kinds of ores.

\subsection{Effects of Other Factors on Reduction Behavior}

Fuwa and Ban-ya ${ }^{25)}$ had carried out the gaseous reduction of various iron ores and reported that the formation of fibrous iron occurred frequently in most of ores more and less and did not depend on the kind of iron oxides such as hematite, magnetite, and rimonite. Similar results would be also found out in this work using a number of ores containing hematite, magnetite, and goethite as a single or mixed phases (Tables 1 and 2). Neuschütz and Hoster' ${ }^{1}$ had reduced 10 kinds of ores in fluidized state with a $90 \% \mathrm{CO}-10 \% \mathrm{H}_{2}$ mixture at $800^{\circ} \mathrm{C}$ and presented the same result as above. 
Miyagawa et al. ${ }^{5)}$ reduced 8 kinds of ores in fluidized state with a $80 \% \mathrm{CO}-20 \% \mathrm{H}_{2}$ mixture at $850^{\circ} \mathrm{C}$ and claimed that ores with high alumina content did not stick due to inhibition of sintering metallic iron by alumina. In the present work using a $\mathrm{CO}-\mathrm{CO}_{2}$ mixture, the sticking behavior of ore at $700^{\circ} \mathrm{C}$ had a relation with the alumina content as indicated in Fig. 13, despite no relation at higher temperatures. Excepting ores $\mathrm{J}$ and $\mathrm{S}$ being under a reduced state prior to metallization, the beds stick below $1.3 \% \mathrm{Al}_{2} \mathrm{O}_{3}$ and fluidize above $2.1 \% \mathrm{Al}_{2} \mathrm{O}_{3}$. Ore I could fluidize due to an high $a_{\mathrm{S}}$. Ore $\mathrm{C}$ would stick due to an intermediate $a_{\mathrm{s}}$. It is known that traces of alumina dissolved in wustite promotes the formation of dense iron, ${ }^{26,27)}$ different from the action of sulfur inducing porous iron. So that, in order to investigate the results of Fig. 13, it will be important to clarify characteristics of alumina in ores and the relationship between alumina and sulfur for product morphology.

Kobayashi et al. ${ }^{28)}$ reduced in $\mathrm{CO}$ base gas Wabush ore $\left(\mathrm{Fe}_{3} \mathrm{O}_{4}, 0.016 \% \mathrm{~S}\right)$ and $\mathrm{Mt}$. -Wright ore $\left(\mathrm{Fc}_{3} \mathrm{O}_{4}\right.$, $0.007 \% \mathrm{~S}$ ), whose alumina contents were in low level for both ores, and observed fibrous irons in the former ore. This result may be able to be explained by different amounts of sulfur species gasified from ores. They also observed numerous iron whiskers for chemical reagent $\mathrm{Fe}_{2} \mathrm{O}_{3}\left(0.01 \% \mathrm{SO}_{4}\right)$. This suggests that the reduction had proceeded under a middle sulfur activity. Assuming that both reactions of reduction and desulfurization during metallization of the reagent in $\mathrm{CO}$ at $900^{\circ} \mathrm{C}$ occur alike under gas starvation control $a_{\mathrm{s}}$ becomes 0.11 .

de Haas et al. ${ }^{29)}$ reduced magnetite ores with a $40 \% \mathrm{CO}-60 \% \mathrm{~N}_{2}$ mixture at $900^{\circ} \mathrm{C}$, and observed markedly fibrous irons by the addition of $5-50 \mathrm{ppm}$ $\mathrm{SO}_{2}$. Because $P_{C O S} / P_{\mathrm{CO}}$ in gas is calculated to be $1.8 \times 10^{-5}-1.8 \times 10^{-4}$ based on the same assumption as above, their sulfur activity range coincides with this work.

Previous studies revealed that alkali has a smaller effect than sulfur for producing iron whiskers. ${ }^{13,15}$ ) The alkali species existing in ore which enhances the

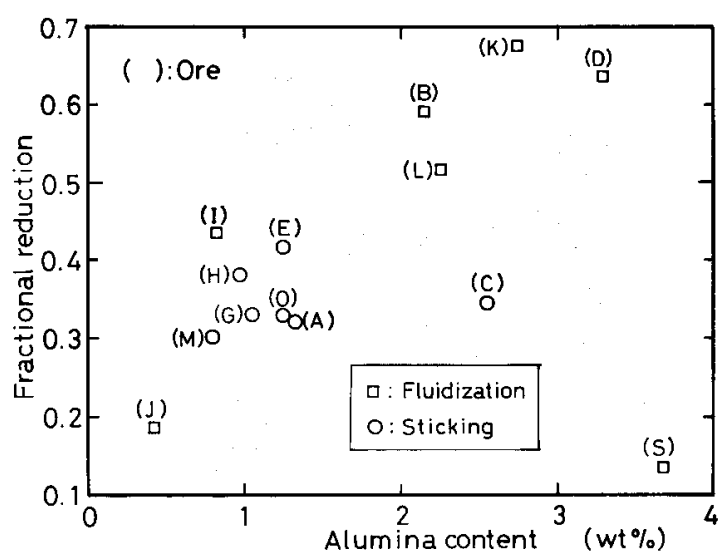

Marks $L, M, S$, and $\mathcal{N}$ arc referred to Fig. 6 . Reduction time of each test is shown in Fig. 8.

Fig. 13. Effect of $\mathrm{Al}_{2} \mathrm{O}_{3}$ content on reduction behavior at $700^{\circ} \mathrm{C}$. formation of whiskers is probably binding with iron oxides, not with silica. ${ }^{15)}$ The former can be analyzed by means of hot hydrochloric acid extraction as shown in Table 1. Because most of these contents $\left(\mathrm{Na}_{2} \mathrm{O}+\right.$ $\mathrm{K}_{2} \mathrm{O}$ ) are in much lower levels except ore I, it will be not necessary to take into account alkalis for morphology change in spite of the coexistence condition of alkali and sulfur markedly favorable to the whisker formation. ${ }^{15)}$

\section{Conclusion}

The values of the sulfur activity in bed during metallization of ore $\left(a_{\mathrm{s}}\right)$, which had a corresponding relation with sulfur content in each ore except Taharoa ore, was in the range of 0.01-1 for all of tests. Many of reduction tests were fell into a sticking at higher temperatures with iron whiskers. The conditions around a middle activity $\left(a_{\mathrm{s}}=0.1\right)$, where long iron whiskers ( $L$ type) appeared at 900 and $800^{\circ} \mathrm{C}$ and short iron whiskers ( $S$ type) at $700^{\circ} \mathrm{C}$, led to a sticking soon after initial metallization. The conditions showing the activities less and more than the above condition, where iron whiskers of $S$ type and porous or plain irons were observed, presented a fluidization state with higher reduction degrees at lower temperatures.

The sulfur activity and the temperature dependences of iron morphology agreed nearly with those of abnormal swelling studied early by authors. As a whole, the sticking tendency of bed coincided with the iron morphology change. Though these results had no relation with the kind of iron oxides in ores, those obtained at $700^{\circ} \mathrm{C}$ were certainly concerned in alumina content of ore.

\section{Acknowledgments}

The authors wish to thank Prof. T. Cho, Nagoya University, Asso. Prof. S. Mori, Nagoya Institute of Technology, and Kobe Steel Ltd. for their various supports. Also the experimental assistance of Mr. M. Kitagawa, now with Suzuki Motor Ltd., is acknowledged.

\section{REFERENCES}

I) D. Neuschütz and T. Hoster: Steel Res., 60 (1989), 113.

2) T. Hamada: Tetsu-to-Hagané, 72 (1986), 1991.

3) M. Tokuda and S. Kobayashi: Proc. 7th PTD Conf., ISSAIME, Penn., (1988), 3.

4) S. Kondo: Tetsu-to-Hagané, 60 (1974), 1542.

5) K. Miyagawa, A. Kamijyo and M. Deguchi: CAMP-ISIJ, 2 (1989), 118.

6) A. Okura: Tetsu-to-Hagané, 57 (1971), S8.

7) H. Schenck, W. Wenzel and H. D. Butzmann: Arch. Eisenhüttenwes., 33 (1962), 211.

8) T. Hirata, S. Jue and H.W. Gudenau: CAMP-ISIJ, 1 (1988), 1130.

9) R. Watanabe, K. Shinohara, T. Ashinaga, M. Onoda and K. Mori: Tetsu-to-Hagané, 72 (1986), 1279.

10) T. Shirai and T. Hamada: Chem. Eng., 29 (1965), 995.

11) T. Soma: Telsu-io-Hagané, 51 (1972), 1557.

12) K. Kunitomo and Y. Hayashi: CAMP-ISIJ, 1 (1988), 1129. 
13) S. Hayashi, Y. Iguchi and J. Hirao: Tetsu-to-Hagané, 71 (1985), 1311.

14) S. Hayashi, Y. Iguchi and J. Hirao: Tetsu-to-Hagané, 73 (1987), 1668.

15) S. Hayashi and Y. Iguchi: ISIJ Int., 29 (1989), 642.

16) H. Rausch, A. Saatci, W. Thumm and F. Oeters: Arch. Eisenhüttenwes., 46 (1975), 623.

17) S. Sayama, I. Sekiguchi and Y. Ueda: Tetsu-to-Hagané, 58 (1972), 240.

18) J. S. Sheasby and J. F. Gransden: Can. Met. Quart., 13 (1974), 479.

19) L. von Bogdandy and H. J. Engell: The Reduction of Iron Ores, Springer-Verlag, Berlin, (1971), 38.

20) C. Y. Wen and T. H. Yu: AIChE J., 12 (1966), 610.

21) K. M. Hutchings, J. D. Smith, S. Yörük and R. J. Hawkins: Ironmaking Steelmaking, 14 (1987), 103.
22) R. B. Bird, W. E. Stewart, and E. N. Lightfoot: Transport Phenomena, John Wiley \& Sons, Inc., New York, (1960), 25.

23) S. Hayashi and Y. Iguchi: ISIJ Int., 29 (1989), 596.

24) B. G. Langston and F. M. Stephens, Jr.: J. Met., 12 (1960), 312.

25) T. Fuwa and S. Ban-ya: Trans. Iron Steel Inst. Jpn., 9 (1969), 137.

26) N. Shigematsu and H. Iwai: Tetsu-to-Hagané, 73 (1987), 89.

27) M. Moukassi, M. Gougeon, P. Steinmetz, B. Dupre and G. Gleitzer: Metall. Trans. B, 15B (1984), 383.

28) M. Kobayashi, H. W. Gudenau, W. G. Burchard and H. C. Schaefer: Tetsu-to-Hagané, 71 (1985), 1102.

29) H. de Haas, K. Grebe and F. Oeters: Arch. Eisenhüttenwes., $51(1980), 167$. 